\title{
EGFR monoclonal antibody panitumumab inhibits chronic proliferative cholangitis by downregulating EGFR
}

\author{
SAN-HU LIU ${ }^{1,2}$, XUE-FANG CHEN $^{1}$, ZHI-BIN XIE ${ }^{1}$ and JIE ZHOU ${ }^{1}$ \\ ${ }^{1}$ Department of Hepatobiliary Surgery, Nanfang Hospital, Southern Medical University, Guangzhou, Guangdong 510515; \\ ${ }^{2}$ Department of Hepatobiliary Surgery, The First People's Hospital of Yueyang, Yueyang, Hunan 414000, P.R. China
}

Received July 18, 2018; Accepted April 16, 2019

DOI: $10.3892 / \mathrm{ijmm} .2019 .4190$

\begin{abstract}
In hepatolithiasis, chronic proliferative cholangitis (CPC), an active and longstanding inflammation of stone-containing bile ducts with enhanced mucin-producing activity, not only affects the progression of the disease, it can also induce biliary carcinogenesis. The present study aimed to examine the effect of the epidermal growth factor receptor (EGFR) monoclonal antibody panitumumab (Pani) on CPC. Following the establishment of CPC rat models, periodic acid Schiff staining was used to observe the positive rate of EGFR expression. The expression levels of EGFR, mucin 5AC (MUC5AC), Ki-67, type I collagen and mammalian target of rapamycin (mTOR), and the activity of $\beta$-glucuronidase $(\beta-\mathrm{G})$, were measured. The rats treated with Pani demonstrated a significantly lower degree of hyperproliferation of the epithelium and submucosal glands of the bile duct and collagen fibers of the bile duct wall, a significantly decreased positive rate of EGFR, reduced phosphorylation of mTOR, decreased expression of EGFR, MUC5AC, Ki-67 and type I collagen, and reduced $\beta-G$ activity. The therapeutic effects in rats treated with 4 and $6 \mathrm{mg} / \mathrm{kg}$ of Pani were more marked than those in rats treated with $2 \mathrm{mg} / \mathrm{kg}$ of Pani. Collectively, the data obtained in the present study suggest that the EGFR monoclonal antibody Pani can effectively inhibit the excessive proliferation and stone-forming potential of bile duct mucosa in $\mathrm{CPC}$ with a receptor saturation effect. Therefore, Pani offers promise as a treatment for the prevention and control of intrahepatic choledocholithiasis caused by CPC.
\end{abstract}

Correspondence to: Dr Jie Zhou, Department of Hepatobiliary Surgery, Nanfang Hospital, Southern Medical University, 1838 Guangzhou Avenue North, Guangzhou, Guangdong 510515, P.R. China

E-mail: zhoujiezj54@163.com

Key words: epidermal growth factor receptor, panitumumab, chronic proliferative cholangitis, intrahepatic choledocholithiasis

\section{Introduction}

Hepatolithiasis is a prevalent disease in Southeast Asia, and proliferative cholangitis (PC) serves an important role in the pathogenesis of hepatolithiasis and is correlated with $\sim 75 \%$ of hepatolithiasis cases in Asia (1). Previously, it was confirmed that chronic PC (CPC) is a pathological foundation and the key contributor to the high recurrence rate of intrahepatic stones and biliary restenosis in patients with hepatolithiasis $(2,3)$. $\mathrm{CPC}$, as an active and long-term inflammation of stone-bearing bile ducts with increased secretion of mucin-like glycoprotein, not only facilitates the progression of hepatolithiasis, it may contribute to biliary carcinogenesis (4). CPC is induced by the formation of stones in the bile ducts and may persist extensively within the bile ducts even following removal of the stone (5), facilitating the formation of new stones and leading to cholestasis (1). It has been shown that chemical biliary duct embolization can uproot CPC and prevent the recurrence of intrahepatic stones, however, its use is restricted as it completely destroys the hepatic segment and related bile ducts (6). Therefore, it is necessary to identify more effective regimens for CPC.

Panitumumab (Pani), an immunoglobulin (Ig)G2 monoclonal antibody directed against epidermal growth factor receptor(EGFR), is effective in 10-20\% patients with unselected metastatic colorectal cancer (mCRC) and promotes the progression-free survival rate of patients with showing disease progression of mCRC following standard chemotherapy (7-9). Formerly known as ABX-EGF, Pani can be applied for the clinical treatment of solid tumors and is directed against the extracellular receptor, leading to the inhibition of critical downstream signaling pathways that control apoptosis, proliferation and differentiation in normal and tumor cells (10). The antitumor activity of Pani has been verified in vivo and in vitro, and the suppression of tumor growth has been investigated in various types of cancer (10). Additionally, Pani has a favorable tolerability profile when administered as a monotherapy (11); Pani is associated with dermatologic toxicity and appears to have a low risk of immunogenicity, but is rarely a severe event associated with EGFR inhibitors $(12,13)$. Furthermore, it has been reported that EGFR can serve as a target in the treatment of proliferative cholangitis in hepatolithiasis (14). Therefore, the present study was performed to examine the effect of the EGFR monoclonal antibody Pani on the excessive proliferation 
and stone-forming potential of the bile duct mucosa in CPC, which may benefit the development of promising treatment strategies for the treatment of CPC.

\section{Materials and methods}

Ethics statement. All animal experiments performed in the present study conformed to the management of local laboratory animal guidelines and Medical Ethics Committee of Nanfang Hospital (Guangzhou, China). All efforts were made to minimize the suffering of animals during the experiment.

Establishment of CPC models and rat grouping. A total of 50 male Sprague-Dawley rats of clean grade (aged two months old; weighing 220-250 g) were purchased from Shanghai Laboratory Animal Center of the Chinese Academy of Sciences (Shanghai, China). The rats were maintained at a humidity of $5-10 \%$ and at $22-25^{\circ} \mathrm{C}$ under a cycle of 12 -h light and $12-\mathrm{h}$ darkness with free access to food and drinking water (acidified water at $\mathrm{pH}=2.5-2.8$ ). The rats were randomly assigned into five groups according to different treatment approaches: Sham group, CPC group (rats of the CPC model without any treatment), $2 \mathrm{mg} / \mathrm{kg}$ Pani group (rats of the CPC model treated with $2 \mathrm{mg} / \mathrm{kg}$ of Pani), $4 \mathrm{mg} / \mathrm{kg}$ Pani group (rats of the CPC model treated with $4 \mathrm{mg} / \mathrm{kg}$ of Pani) and $6 \mathrm{mg} / \mathrm{kg}$ Pani group (rats of the CPC model treated with $6 \mathrm{mg} / \mathrm{kg}$ of Pani). The CPC model was established according to the following protocol (1): The rats were anesthetized with $10 \%$ chloral hydrate $(300 \mathrm{mg} / \mathrm{kg}$, no signs of peritonitis were observed at this concentration), a 5-0 nylon thread was inserted into the hepatic portal reversely from the duodenal papilla to the common bile duct, and the poke hole at the end of the suture was sutured. After 7 days of modeling, the bile duct wall was thickened, and hyperplasia of the mucosa epithelium and collagen fibers was observed by microscopy, indicating that the modeling was successfully established. In the sham group, the abdominal cavity of the rats was opened and then closed without any other treatment. During the modeling, in the rats treated with different doses of Pani, a No. 20 venous indwelling needle was threaded with a nylon thread, and Pani $(20 \mathrm{mg} / \mathrm{ml})$ at a dose of 2,4 or $6 \mathrm{mg} / \mathrm{kg}$ was injected into the common bile duct. The rats in each group were intraperitoneally injected with 5-bromo-2'-deoxyuridine (BrdU) at a dose of $100 \mathrm{mg} / \mathrm{kg}$ on days 4,5 and 6 post-treatment. On day 7 post-treatment, all rats were sacrificed by barbiturate overdose (150 mg/kg pentobarbital sodium, i.v.) (15) and bile duct tissue specimens were extracted by laparotomy for further experiments.

Hematoxylin and eosin $(H \& E)$ staining. The bile duct tissues of each group were immersed in $10 \%$ neutral formaldehyde solution, and paraffin sections were prepared. The specimens were fixed with $10 \%$ neutral formaldehyde solution, dehydrated in alcohol, cleared twice with xylene, immersed in wax, embedded in paraffin and cut into 4- $\mu \mathrm{m}$ sections. Thereafter, the paraffin sections were sliced continuously and placed in an oven at $80^{\circ} \mathrm{C}$ for $1 \mathrm{~h}$. Following cooling, the sections were dehydrated in conventional gradient alcohol, cleared with xylene and then washed with PBS. The sections were stained with hematoxylin (H8070; $5 \mathrm{~g}$; Beijing Solarbio Science \& Technology Co., Ltd., Beijing, China) for $3 \mathrm{~min}$, removed and washed. The sections were then differentiated with hydrochloric acid alcohol for $10 \mathrm{sec}$, washed and soaked for $5 \mathrm{~min}$, and reconverted to blue with ammonia for $10 \mathrm{~min}$, followed by staining with eosin solution (cat. no. PT001; Shanghai Bogoo Biological Technology Co., Ltd., Shanghai, China) for a few seconds. Thereafter, the sections were dehydrated with gradient alcohol for $1 \mathrm{~min} /$ time and cleared twice with xylene (1 min/time). In the ventilator, following mounting of the sections with neutral gum, pathological changes were observed under an optical microscope (DMM-300D; Shanghai Caikon Optical Instrument Co., Ltd., Shanghai, China).

Masson staining. The bile duct tissue sections were dewaxed conventionally, washed with distilled water, stained with Ponceau (cat. no. RTD6301; Real-Times Biotechnology Co., Ltd., Beijing, China) for $2 \mathrm{~min}$ and mordanted with 5\% phosphomolybdate solution (cat. no. P1910-100G; Shanghai Regal Biology Technology Co., Ltd., Shanghai, China) for 2 min. Following staining with methyl green (cat. no. BI005; Shanghai Regal Biology Technology Co., Ltd.) for $3 \mathrm{~min}$, the sections were color-separated with $95 \%$ alcohol, dehydrated with $100 \%$ alcohol, cleared with xylene and mounted with neutral gum. Subsequently, the sections were observed under a polarized light microscope (XPT-480; Shanghai Zhongheng Co., Ltd., Shanghai, China) and analyzed by Image Pro- 6 software (Media Cybernetics Inc., Bethesda, MD, USA). The collagen fibers were stained bluish green, muscle fibers and cellulose were stained pink, and cells were stained orange red.

Vitoria blue Ponceau $S$ (VBPS) staining. The bile duct tissue sections were dewaxed conventionally, washed with $70 \%$ ethanol solution for $2 \mathrm{~min}$, immersed in Vitoria blue B staining solution (YML5840; Shanghai Youyu Biological Technology Co., Ltd., Shanghai, China) for $2 \mathrm{~h}$, stained with $95 \%$ ethanol solution for $2 \mathrm{sec}$, washed with distilled water for $2 \mathrm{~min}$, and stained with Ponceau S staining solution (cat. no. C0039; Shanghai Baoman Biological Technology Co., Ltd., Shanghai, China) for $4 \mathrm{~min}$. Following drying with absorbent paper, the sections were immediately soaked twice with absolute ethyl alcohol, dried directly in air, cleared with xylene and mounted with neutral gum following air drying in the ventilator. The collagen fibers stained with red were observed under an optical microscope for quantitative analysis (DMM-300D; Shanghai Caikon Optical Instrument Co., Ltd.).

Periodic acid Schiff (PAS) staining. The bile duct tissues of each group were collected and treated with acetylaminofluorene solution, Carnoy's solution or at low temperature in the refrigerator. The sections were dehydrated with absolute ethyl alcohol, cleared with xylene, immersed in wax and embedded in paraffin, cut into $5-\mu \mathrm{m}$ sections and dehydrated again. Subsequently, the sections were oxidized with $0.5-1 \%$ periodic acid for 5-10 min. The ambient temperature did not exceed $20^{\circ} \mathrm{C}$ in order to prevent reduction in the oxidation time. Thereafter, the sections were washed under running water for 5 min, rinsed twice with distilled water, stained with Schiff solution protected from light and rinsed twice with $0.5 \%$ sodium metabisulfite (1-2 min/time for differentiation). The sections were then washed under running water for 5-10 $\mathrm{min}$, washed with distilled water, stained with Harris hematoxylin 
for 2-5 min, washed under running water, differentiated using $1 \%$ hydrochloric acid, rinsed under running water and reconverted to blue with $1 \%$ ammonia. Finally, the sections were rinsed under running water, conventionally dehydrated, cleared with xylene and mounted using neutral gum. Mucin-like glycoprotein stained purplish red was observed under an optical microscope (DMM-300D; Shanghai Caikon Optical Instrument Co., Ltd.) for quantitative analysis with the Image Pro-6 software.

Immunohistochemistry. The bile duct tissue sections were conventionally dewaxed and then incubated in 3\% hydrogen peroxide at room temperature for $15 \mathrm{~min}$ to eliminate endogenous peroxidase. The antigen was repaired in $0.01 \mathrm{~mol} / \mathrm{l}$ citric acid buffer solution ( $\mathrm{pH}$ 6.0) in a microwave for $10 \mathrm{~min}$ and was naturally cooled down. Subsequently, the sections were sealed in 5\% normal goat serum (Abcam, Cambridge, MA, USA) at room temperature for $15 \mathrm{~min}$ and were incubated with rabbit monoclonal primary antibody specific to EGFR (cat. no. ab52894; $1: 100$ ) overnight at $4^{\circ} \mathrm{C}$. Following incubation at room temperature for $40 \mathrm{~min}$, the sections were incubated with horseradish peroxidase (HRP)-labeled goat-anti rabbit immunoglobulin G (IgG; cat. no. ab205718; 1:2,000) for $1 \mathrm{~h}$ at $37^{\circ} \mathrm{C}$ and HRP-labeled streptavidin for $15 \mathrm{~min}$. During the intervals of the above steps, the sections were washed twice with $0.01 \mathrm{~mol} / 1 \mathrm{PBS}(\mathrm{pH} 7.4$ ) for $5 \mathrm{~min} /$ time. The above antibodies were purchased from Abcam. Thereafter, the sections were stained with diaminobenzidine (DAB) for 3-5 min, fully washed with double-distilled water; counterstained with hematoxylin for 1-3 min, dehydrated conventionally, cleared and sealed using neutral gum. The results were observed and images were captured using a Primo Star digital microscope (Motic China Group Co., Ltd., Guangzhou, China). Following random grouping and design, EGFR-positive expression was observed as a yellow-stained cytoplasm and cell membrane (magnification, x100). Each slice was continuously observed for five high-power fields. In each field, 200 cells were counted in total, and the number of positive cells and negative cells in each high-power field was counted. Finally, the mean cell numbers were calculated. The SP staining kit was purchased from Shanghai Blue Gene for Life Science Biotechnology Co., Ltd. (Shanghai, China), and the DAB chromogenic kit was purchased from Beijing Zhongshan Jinqiao Biotechnology Co., Ltd. (Beijing, China).

Reverse transcription-quantitative polymerase chain reaction $(R T-q P C R)$ analysis. The total RNA of bile duct tissues of each group was extracted with TRIzol RNA extract (Invitrogen; Thermo Fisher Scientific, Inc. Waltham, MA, USA). Reverse transcription of cDNA was conducted according to the instructions of the Primescript ${ }^{\mathrm{TM}}$ RT reagent kit (cat. no. RRO37A; Takara Biotechnology, Co., Ltd., Dalian, China). Following successful transcription, the target genes and internal reference genes were amplified by fluorescence qPCR (ABI 7500; Applied Biosystems; Thermo Fisher Scientific, Inc.) with glyceraldehyde-3-phosphate dehydrogenase (GAPDH) used as the internal reference. The reaction conditions were indicated as follows: Pre-denaturation for $10 \mathrm{~min}$ at $95^{\circ} \mathrm{C}$, and 40 cycles of $10 \mathrm{sec}$ at $94^{\circ} \mathrm{C}$ (denaturation), $20 \mathrm{sec}$ at $60^{\circ} \mathrm{C}$ (annealing) and $34 \mathrm{sec}$ at $72^{\circ} \mathrm{C}$ (extension). The mRNA levels of EGFR and mucin 5AC
Table I. Primer sequences for reverse transcription-quantitative polymerase chain reaction analysis.

Gene Sequence

\begin{tabular}{ll}
\hline EGFR & Forward: 5'-CCCACTCATGCTCTACAACC-3' \\
& Reverse: 5'-GCCGGTATGATTTCTAGGT-3' \\
MUC5AC & Forward: 5'-AGCACAGTTGCCTCAAGTCC-3' \\
& Reverse: 5'-CTCGGCTACAGGTCCATCC-3' \\
GAPDH & Forward: 5'-CGTCTTCACCACCATGGAGA-3' \\
& Reverse: 5'-GCCAGTAGACTCCACGACAT-3'
\end{tabular}

EGFR, epidermal growth factor receptor; MUC5AC, mucin 5AC; GAPDH, glyceraldehyde-3-phosphate dehydrogenase.

(MUC5AC) were calculated using the $2^{-\Delta \Delta \mathrm{Cq}}$ method (16). The formula was as follows: $\Delta \Delta \mathrm{Cq}=\Delta \mathrm{Cq}_{\text {experimental group }}-\Delta \mathrm{Cq}_{\text {control group }}$, and $\Delta \mathrm{Cq}=\mathrm{Cq}_{\text {target gene }}-\mathrm{Cq}_{\mathrm{GAPDH}} \cdot \mathrm{Cq}$ refers to the amplified cycle number when the real-time fluorescence intensity of the reaction reaches the set threshold. The experiment was conducted three times, and the primer sequences are presented in Table I.

Western blot analysis. The total protein in the bile duct tissues was extracted using a protein lysis buffer (cat. no. C0481; Sigma-Aldrich; Merck KGaA, Darmstadt, Germany), and the protein was quantified using the bicinchoninic acid method. Subsequently, $10 \%$ sodium dodecyl sulfate-polyacrylamide gel electrophoresis was performed. To each well, $20 \mu \mathrm{g}$ of protein loading sample was added, which was then mixed with sample loading buffer solution and boiled for $5 \mathrm{~min}$ at $100^{\circ} \mathrm{C}$. Following cooling in an ice bath and centrifugation at $258 \mathrm{x} \mathrm{g}$ for $20 \mathrm{~min}$ at $4^{\circ} \mathrm{C}$, the sample was loaded into each lane equally by a microinjector for electrophoretic separation. Following electrophoresis, the protein on the gel was transferred onto a nitrocellulose membrane. The membrane was blocked with $5 \%$ skimmed milk powder and incubated with rabbit monoclonal antibody specific to EGFR $(1 \mu \mathrm{g} / \mathrm{ml}$; cat. no ab52894) and Ki-67 (1 $\mu \mathrm{g} / \mathrm{ml}$; cat. no. ab16667), rabbit polyclonal antibody specific to type I collagen $(1 \mu \mathrm{g} / \mathrm{ml}$; cat. no. ab34710), rabbit polyclonal antibody specific to mammalian target of rapamycin (mTOR; $0.5 \mu \mathrm{g} / \mathrm{ml}$; cat. no. ab2732), and rabbit monoclonal antibody specific to phosphorylated (p-)mTOR ( $1 \mu \mathrm{g} / \mathrm{ml}$; cat. no. ab137133) overnight at $4^{\circ} \mathrm{C}$. The following day, the membrane was washed three times with Tris-buffered saline containing 1\% Tween 20 (TBST) for $5 \mathrm{~min} /$ time and was incubated with HRP-labeled goat-anti rabbit antibody specific to $\operatorname{IgG}(0.5 \mu \mathrm{g} / \mathrm{ml}$; cat. no. ab205718) at room temperature for $1.5 \mathrm{~h}$. The above antibodies were purchased from Abcam. The membrane was washed with TBST again, and protein expression was observed using $1 \mathrm{ml}$ chemiluminescence reagent (prepared in accordance with SuperSignal ${ }^{\circledR}$ West DuraExtended Duration Substrate). The excess liquid was discarded, and the membrane was wrapped with a fresh film. In a dark room, the membrane was exposed to X-ray film for 5-10 min, following which the membrane was developed and fixed. GAPDH served as the internal reference. The relative expression of EGFR, Ki-67 and type I collagen was calculated by the ratio of the optical density (OD) value of 

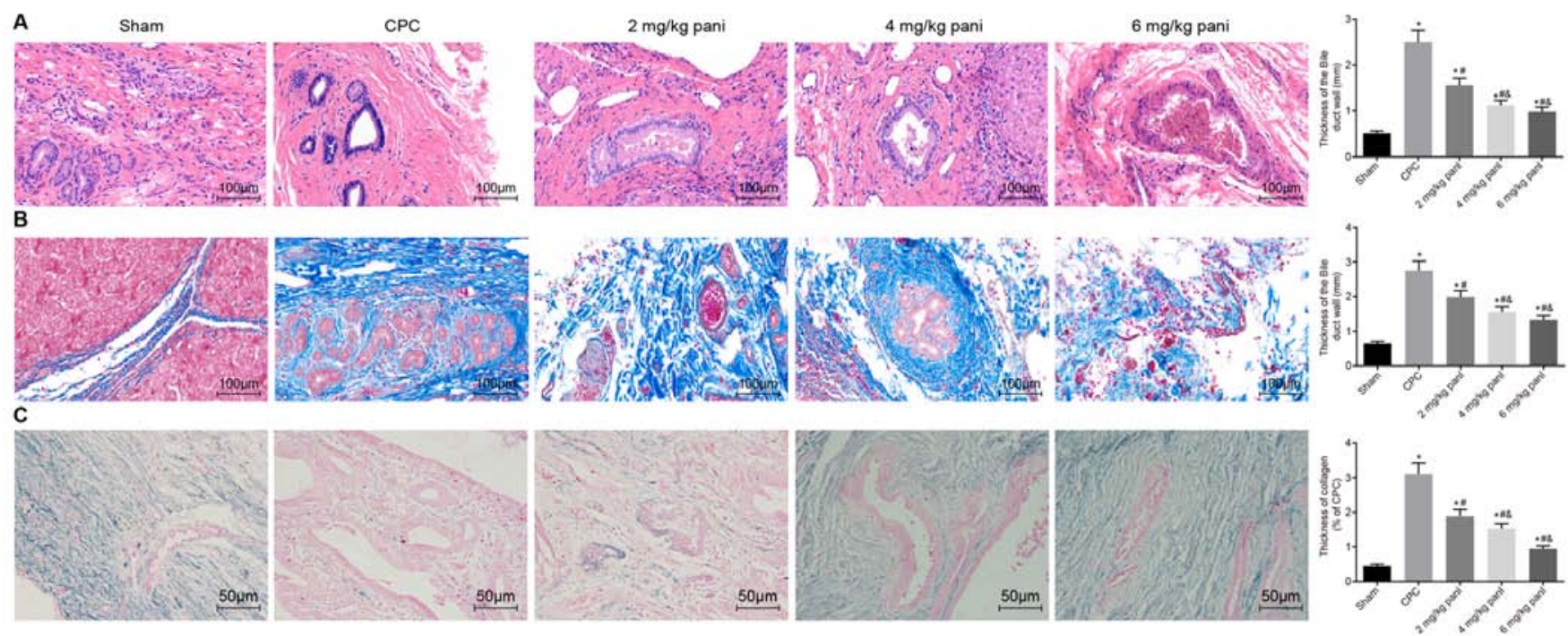

Figure 1. Pathological observation of bile duct tissues in each group following CPC model establishment. (A) Hematoxylin and eosin staining showing the pathology of bile duct tissues in rats (magnification, x100) and the bile duct wall thickness. (B) Pathology of the bile duct tissues in the rats of each group observed by Masson staining (magnification, x100). (C) Pathology of bile duct tissues in the rats of each group observed by Vitoria blue Ponceau S staining (magnification, $\mathrm{x} 200)$ and the collagenous fiber thickness $(\mathrm{n}=10)$. Differences among the groups were analyzed by one-way analysis of variance. ${ }^{*} \mathrm{P}<0.05$ vs. sham group; ${ }^{\text {P }}<0.05$ vs. CPC group; ${ }^{\circledR} \mathrm{P}<0.05$ vs. $2 \mathrm{mg} / \mathrm{kg}$ Pani group. Pani, panitumumab; $\mathrm{CPC}$, chronic proliferative cholangitis.

EGFR, Ki-67 and type I collagen to the average gray value of the developing imaging of the GAPDH band, and gray value analysis was performed using ImageJ software (version 1.8.0; National Institutes of Health, Bethesda, MD, USA). The experiment was repeated three times.

Immunofluorescence assay. The frozen sections of the bile duct wall were incubated with rabbit polyclonal antibody specific to BrdU (1:100; cat. no. ab152095) overnight at $4^{\circ} \mathrm{C}$. The sections were washed with PBS three times and were then incubated with goat-anti rabbit antibody specific to $\operatorname{IgG}$ (1:200; cat. no. ab150077) labeled with Alexa Fluor 488, and then were incubated at $37^{\circ} \mathrm{C}$, washed three times with PBS protected from light, and mounted. The above antibodies were purchased from Abcam. A laser scanning confocal microscope (Carl Zeiss AG, Oberkochen, Germany) was used to observe the results. The results showed that the emission wavelength of Alexa Fluor 488 was $519 \mathrm{~nm}$ using NIS-Elements Viewer software (v4.2.0; Nikon Instruments, Inc., Melville, NY, USA). The BrdU-positive cells showed blue fluorescence staining.

Determination of $\beta$-glucuronidase ( $\beta$-G) activity. Using $\beta-\mathrm{G}$ phenolphthalein as the substrate, the activity of $\beta-G$ was quantitatively determined under the condition of $\mathrm{pH} 4.95$ using the modified Fisherman method (17). The experiment was repeated three times.

Statistical analysis. The data were analyzed using SPSS 21.0 software (IBM Corp, Armonk, NY, USA). The measurement data are presented as the mean \pm standard deviation, and all data were tested for the normality of distributions and homogeneity of variance. Differences among groups were analyzed by one-way analysis of variance, and pairwise comparisons among multiple groups were checked using Tukey's test. $\mathrm{P}<0.05$ was considered to indicate a statistically significant difference.

\section{Results}

Pathological observation of bile duct tissues in each group following CPC modeling. Following model construction, the rats of the CPC model were treated with 2, 4 or $6 \mathrm{mg} / \mathrm{kg}$ Pani, respectively. Bile duct specimens were collected to observe the pathological characteristics and the diameter of the bile duct in each group was measured. Pathological observation of the cholangitis tissues extracted from the sham-operated and CPC rats with or without Pani treatment was performed by H\&E staining (Fig. 1A), Masson staining (Fig. 1B) and VBPS staining (Fig. 1C). Compared with the sham group, the pathological changes of the cholangitis tissues in the CPC group were as follows: H\&E staining revealed hyperplasia of the mucosa epithelium appearing villous in the lumen of the bile duct. The microtissue of the hyperplastic bile duct wall encapsulated the gland of the bile duct wall, mucus stagnation and expansion of the adenoid cavity. Masson staining showed that the bile duct walls and perivascular collagen fibers were proliferated in large numbers. Hyperplasia of the collagen fibers wrapped the submucosal glands. VBPS staining showed a significant increase in collagen fiber thickness. Compared with the CPC group, a shorter diameter of the bile duct, thinner bile duct wall, less fibrous tissues and submucosal gland and thinner collagen fibers were found in the $2 \mathrm{mg} / \mathrm{kg}$ Pani group, and the pathological changes were gradually improved; compared with the $2 \mathrm{mg} / \mathrm{kg}$ Pani group, the diameter of the bile duct became shorter, the bile duct wall was thickened, the thickness of the collagen fibers and the degree of inflammation were reduced in the 4 and $6 \mathrm{mg} / \mathrm{kg}$ Pani groups, and the texture was soft $(P<0.05)$; these trends differed from those in the sham group $(\mathrm{P}<0.05)$. No significant difference in pathology was found between the $4 \mathrm{mg} / \mathrm{kg}$ Pani group and $6 \mathrm{mg} / \mathrm{kg}$ Pani group $(\mathrm{P}>0.05)$.

EGFR monoclonal antibody Pani inhibits the release of mucin-like glycoproteins. Mucin serves an important role 


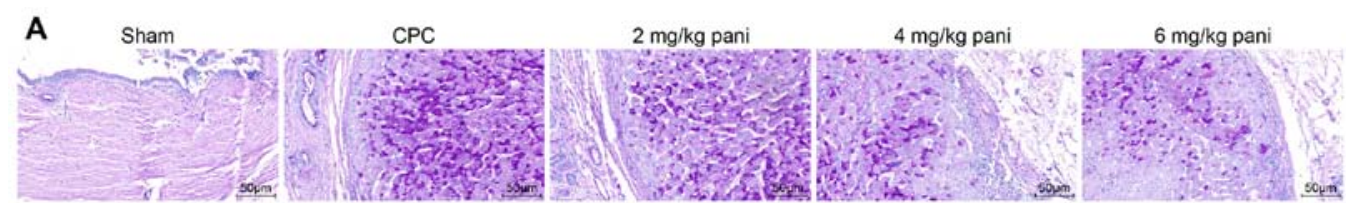

B

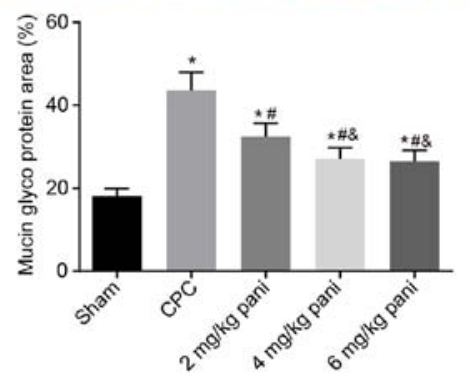

Figure 2. EGFR monoclonal antibody Pani inhibits the secretion of mucin-like glycoproteins in the bile duct wall glands. (A) Period acid Schiff staining of rat bile duct tissues (magnification, $\mathrm{x} 100$ ). (B) Percentage of mucin-like glycoprotein in bile duct tissues in each group (n=10). Differences among the groups were analyzed by one-way analysis of variance. ${ }^{*} \mathrm{P}<0.05$ vs. sham group; ${ }^{\sharp} \mathrm{P}<0.05$ vs. CPC group; ${ }^{\circledR} \mathrm{P}<0.05$ vs. 2 mg/kg Pani group. Pani, panitumumab; EGFR, epidermal growth factor receptor; CPC, chronic proliferative cholangitis.

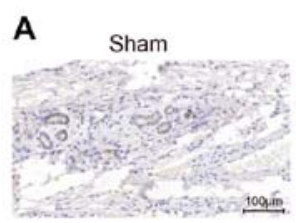

B
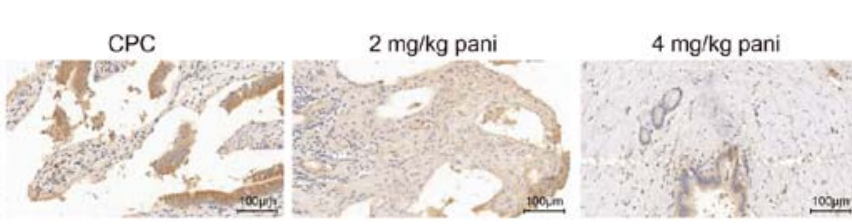

$6 \mathrm{mg} / \mathrm{kg}$ pani

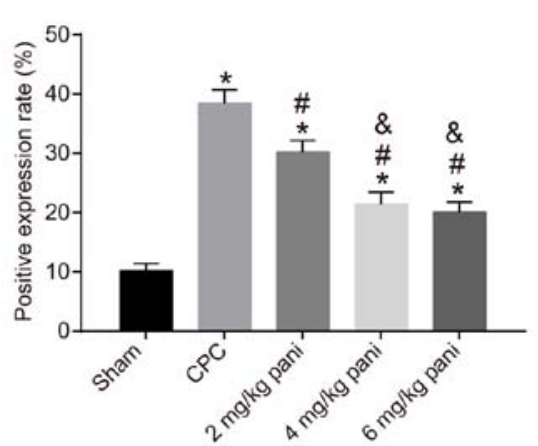

Figure 3. Pani inhibits the positive expression rate of EGFR in the bile duct tissues of rats. (A) Positive expression of EGFR as measured by immunohistochemistry (magnification, x100). (B) Positive expression rate of EGFR in the bile duct tissues of rats in each group (n=10). Data were analyzed by one-way analysis of variance and Tukey's test. ${ }^{*} \mathrm{P}<0.05$ vs. sham group; ${ }^{*} \mathrm{P}<0.05$ vs. CPC group; ${ }^{\circledR} \mathrm{P}<0.05$ vs. 2 mg/kg Pani group. Pani, panitumumab; EGFR, epidermal growth factor receptor; $\mathrm{CPC}$, chronic proliferative cholangitis.

in bile viscosity and the aggregation and deposition of stone-forming elements. In the present study, PAS staining was used to analyze the differential levels of mucin-like glycoproteins in the bile duct tissues of rats. The results are shown in Fig. 2A and B. Mucin can be expressed in the cytoplasm and cell membrane of the mucosa epithelium and submucosal gland. Mucin-like glycoprotein was purple red on PAS staining. Compared with the sham group, PAS staining of the bile duct epithelium and the wall glands of the CPC group was markedly enhanced, presenting as increased positive staining in the cytoplasm and membrane of the bile duct epithelium and submucosal gland. Compared with the sham group, PAS staining in the $2 \mathrm{mg} / \mathrm{kg}$ Pani group was weaker than that in the CPC group $(\mathrm{P}<0.05)$. Additionally, PAS staining in the $4 \mathrm{mg} / \mathrm{kg}$ and $6 \mathrm{mg} / \mathrm{kg}$ Pani groups was weaker than that in the $2 \mathrm{mg} / \mathrm{kg}$ Pani group $(\mathrm{P}<0.05)$ but more marked than that in the sham group $(\mathrm{P}<0.05)$. The results showed that the EGFR monoclonal antibody Pani inhibited the secretion of mucin-like glycoprotein in the bile duct wall, thus effectively reducing the bile viscosity, aggregation and deposition of stone-forming elements.

Pani inhibits the positive rate of EGFR in bile duct tissues. Immunohistochemistry was conducted to measure the positive rates of EGFR expressed in the bile duct tissues of rats. The positive staining of EGFR in the bile duct tissues of each group is shown in Fig. 3A. The cytoplasm and cell membrane were stained brownish yellow, with maximum staining in the cytoplasm. Compared with the sham group, the CPC group showed more EGFR-positive staining in the cytoplasm and cell membrane of the hyperplastic bile duct epithelium and submucosal glands. As shown in Fig. 3B, the positive rate was used as a parameter to quantify the expression of EGFR in each group. The results showed that the positive rate in the $2 \mathrm{mg} / \mathrm{kg}$ Pani group $(30.15 \%)$ was lower than that in the CPC group (38.41\%). Additionally, the positive rates in the $4 \mathrm{mg} / \mathrm{kg}$ 

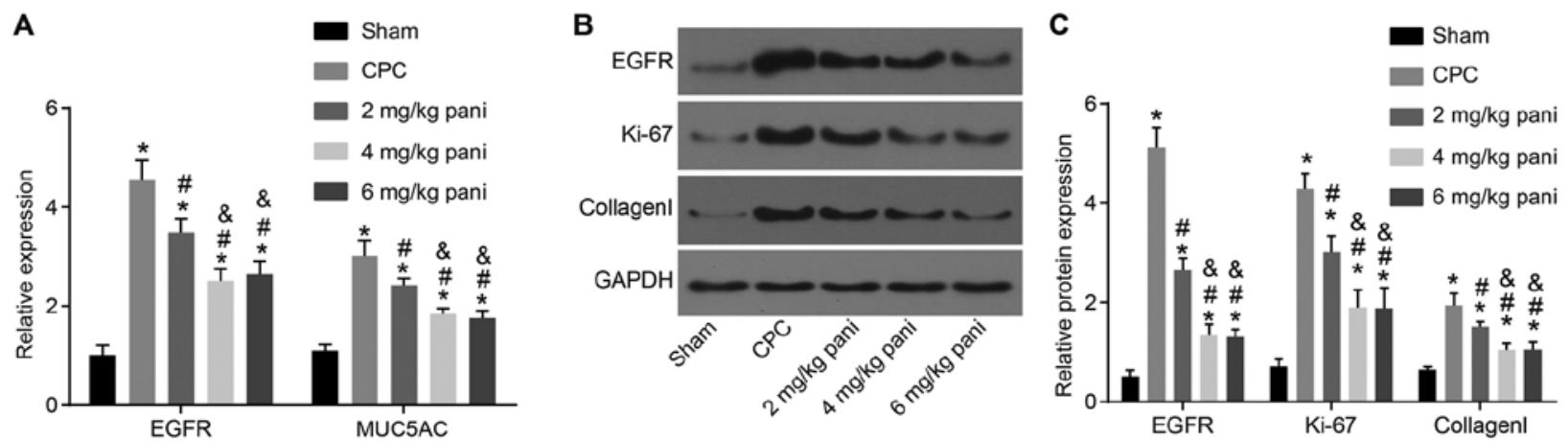

Figure 4. EGFR monoclonal antibody Pani inhibits CPC by downregulating the expression of proliferation-associated genes in bile duct tissues. (A) mRNA levels of EGFR and MUC5AC in the rat bile duct tissues as determined by reverse transcription-quantitative polymerase chain reaction. (B) Gray values of EGFR, Ki-67 and type I collagen protein bands. (C) Protein levels of EGFR, Ki-67 and type I collagen in the rat bile duct tissues in response to treatment with Pani measured as determined by western blot analysis $(\mathrm{n}=10)$. Data were analyzed by one-way analysis of variance and Tukey's test. " $\mathrm{P}<0.05$ vs. sham group; ${ }^{\text {"P }}<0.05$ vs. CPC group; ${ }^{\text {\& }} \mathrm{P}<0.05$ vs. $2 \mathrm{mg} / \mathrm{kg}$ Pani group. Pani, panitumumab; EGFR, epidermal growth factor receptor; CPC, chronic proliferative cholangitis; MUC5AC, mucin 5AC; GAPDH, glyceraldehyde-3-phosphate dehydrogenase.

A

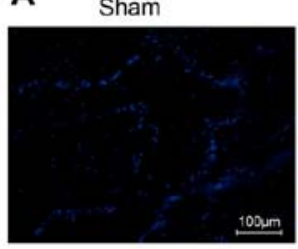

B
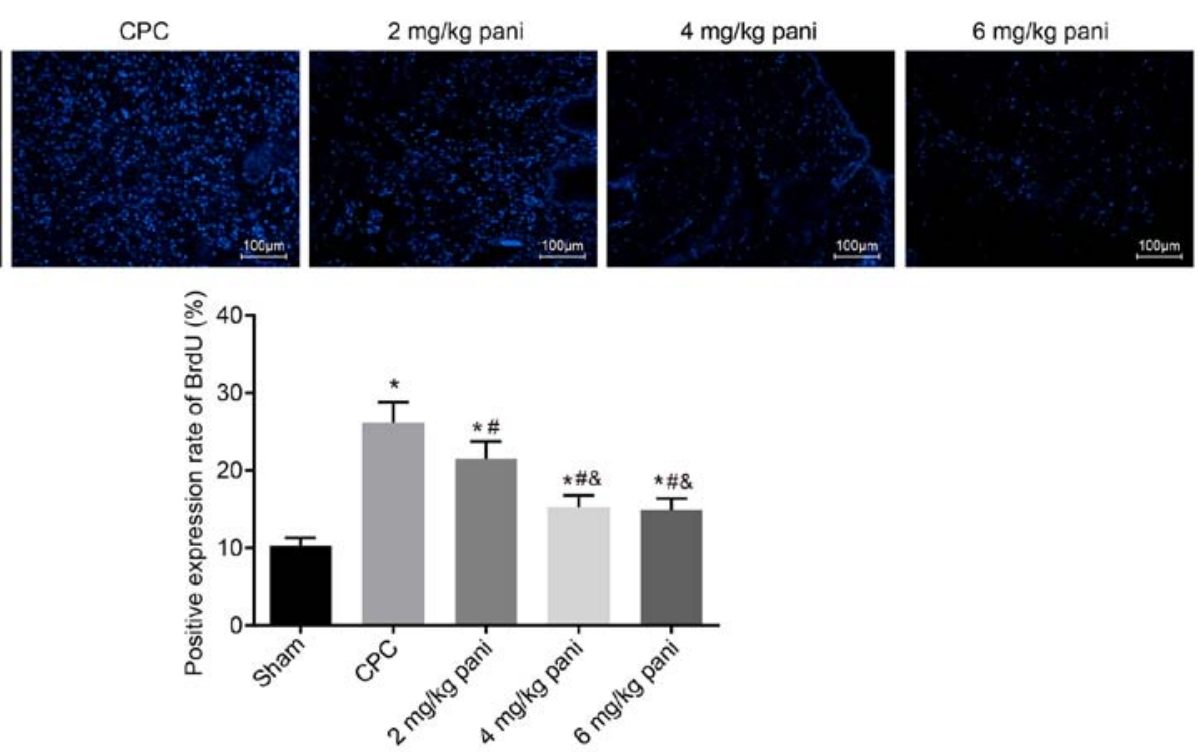

Figure 5. EGFR monoclonal antibody Pani inhibits the BrdU-positive rate in bile duct tissues. (A) Immunofluorescence images of BrdU-positive staining (magnification, $\mathrm{x} 200)$. (B) Positive rate of BrdU in the rat bile duct tissues $(\mathrm{n}=10)$. Data were analyzed by one-way analysis of variance. ${ }^{*} \mathrm{P}<0.05$ vs. sham group; ${ }^{\#} \mathrm{P}<0.05$ vs. CPC group; ${ }^{\&} \mathrm{P}<0.05$ vs. $2 \mathrm{mg} / \mathrm{kg}$ Pani group. Pani, panitumumab; EGFR, epidermal growth factor receptor; CPC, chronic proliferative cholangitis; BrdU, bromodeoxyuridine.

Pani group (21.42\%) and the $6 \mathrm{mg} / \mathrm{kg}$ Pani group $(20.07 \%)$ were lower than that in the $2 \mathrm{mg} / \mathrm{kg}$ Pani group. No marked differences were noted between the $4 \mathrm{mg} / \mathrm{kg}$ Pani group and $6 \mathrm{mg} / \mathrm{kg}$ Pani group, however, the rates were higher than that in the sham group $(8.32 \%)$.

EGFR monoclonal antibody Pani inhibits CPC by downregulating the expression of EGFR and proliferation-associated genes in bile duct tissues. The expression of genes that contribute to the hyperproliferation of collagen fibers in the bile duct wall and that may cause the formation of bile duct stones, including EGFR, Ki-67, type I collagen and MUC5AC, exist in bile duct tissues. Therefore, the expression of these genes was determined in the present study to examine the effect of the EGFR monoclonal antibody Pani on CPC. As shown in Fig. 4A-C, compared with the sham group, the expression levels of EGFR, $\mathrm{Ki}-67$, type I collagen and MUC5AC in the bile duct tissues of the other groups were significantly increased (all $\mathrm{P}<0.05$ ). Compared with the CPC group, the expression levels of EGFR, $\mathrm{Ki}-67$, type I collagen and MUC5AC in bile duct tissues in the 2,4 and $6 \mathrm{mg} / \mathrm{kg}$ Pani groups were notably decreased (all $\mathrm{P}<0.05)$. Compared with the $2 \mathrm{mg} / \mathrm{kg}$ Pani group, the expression levels of EGFR, Ki-67, type I collagen and MUC5AC in the bile duct tissues in the 4 and $6 \mathrm{mg} / \mathrm{kg}$ Pani groups were significantly reduced (all $\mathrm{P}<0.05$ ). No differences were found between the $4 \mathrm{mg} / \mathrm{kg}$ Pani group and $6 \mathrm{mg} / \mathrm{kg}$ Pani group in terms of these genes (all $\mathrm{P}>0.05$ ). The results showed that the EGFR monoclonal antibody Pani inhibited the expression of genes associated with cell proliferation and may cause the formation of bile duct stones, thus inhibiting the overproliferation and potential of $\mathrm{CPC}$ with a receptor-saturation effect.

EGFR monoclonal antibody Pani inhibits the BrdU-positive rate in bile duct tissues. The immunofluorescence assay was 


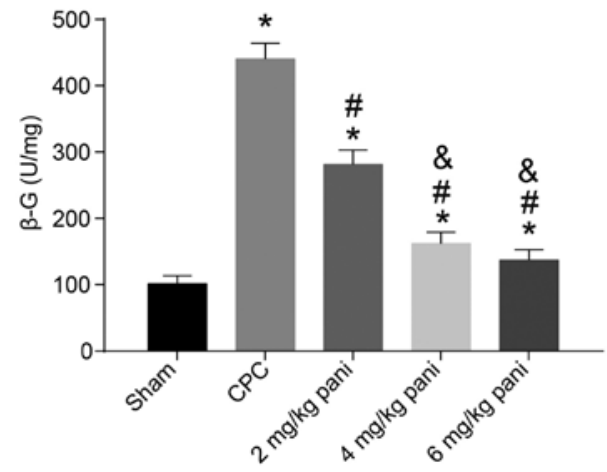

Figure 6. EGFR monoclonal antibody Pani inhibits endogenous $\beta-\mathrm{G}$ activity in the common bile duct wall $(n=10)$. Data were analyzed by one-way analysis of variance and Tukey's test. ${ }^{*} \mathrm{P}<0.05$ vs. sham group; ${ }^{\mathrm{P}} \mathrm{P}<0.05$ vs. $\mathrm{CPC}$ group; ${ }^{\&} \mathrm{P}<0.05 \mathrm{vs} .2 \mathrm{mg} / \mathrm{kg}$ Pani group. Pani, panitumumab; EGFR, epidermal growth factor receptor; $\mathrm{CPC}$, chronic proliferative cholangitis; $\beta-\mathrm{G}, \beta$-glucuronidase.

used to determine the positive rate of BrdU in rat bile duct tissues to examine the effect of EGFR monoclonal antibody Pani on CPC overproliferation. Positive-BrdU was demonstrated with the nucleus showing blue fluorescence. The results (Fig. 5A and B) indicated that, compared with the sham group, the positive rate of BrdU in the CPC group was significantly increased $(\mathrm{P}<0.05)$. Compared with the CPC group, the positive rate of BrdU in the $2 \mathrm{mg} / \mathrm{kg}$ Pani group was notably decreased $(\mathrm{P}<0.05)$. Compared with the $2 \mathrm{mg} / \mathrm{kg}$ Pani group, the positive rates of BrdU in the $4 \mathrm{mg} / \mathrm{kg}$ Pani and $6 \mathrm{mg} / \mathrm{kg}$ Pani groups were markedly reduced $(\mathrm{P}<0.05)$. There were no significant differences between the $4 \mathrm{mg} / \mathrm{kg}$ Pani group and $6 \mathrm{mg} / \mathrm{kg}$ Pani group $(\mathrm{P}>0.05)$. These results showed that the EGFR monoclonal antibody Pani inhibited the positive rate of BrdU, thus inhibiting the overproliferation of CPC, and the efficacy had a receptor-saturation effect.

EGFR monoclonal antibody Pani inhibits endogenous $\beta-G$ activity. Following biliary tract infection, the endogenous $\beta-G$ activity in bile has been shown to be significantly increased in addition to exogenous $\beta-\mathrm{G}$, and this endogenous $\beta-\mathrm{G}$ activity in the bile or liver is significantly increased in patients with bile pigment stones (18), suggesting that $\beta-\mathrm{G}$ is important in the formation of intrahepatic bile duct stones. The present study compared the changes in $\beta-\mathrm{G}$ activity among the sham, CPC, $2 \mathrm{mg} / \mathrm{kg}$ Pani, $4 \mathrm{mg} / \mathrm{kg}$ Pani and $6 \mathrm{mg} / \mathrm{kg}$ Pani groups and further analyzed the effect of the EGFR monoclonal antibody Pani on the stone-formation potential of CPC (Fig. 6). Compared with the sham group, the activity of $\beta-\mathrm{G}$ in the CPC group was significantly increased $(\mathrm{P}<0.05)$. Compared with the CPC group, the activity of $\beta-\mathrm{G}$ in the $2 \mathrm{mg} / \mathrm{kg}$ Pani group was notably decreased $(\mathrm{P}<0.05)$. Compared with the $2 \mathrm{mg} / \mathrm{kg}$ Pani group, the activities of $\beta-\mathrm{G}$ in the 4 and $6 \mathrm{mg} / \mathrm{kg}$ Pani groups were markedly reduced $(\mathrm{P}<0.05)$. There were no significant differences between the 4 and $6 \mathrm{mg} / \mathrm{kg}$ Pani groups $(\mathrm{P}>0.05)$. These results demonstrated that the EGFR monoclonal antibody Pani inhibited the activity of $\beta-G$, thus inhibiting the stone-formation potential of $\mathrm{CPC}$, and the efficacy had a receptor-saturation effect.

EGFR monoclonal antibody Pani downregulates mTOR and its phosphorylation by inhibiting expression of the EGFR gene. The mTOR signaling pathway is important in cell growth and proliferation. In the present study, the extent of mTOR phosphorylation in the bile duct tissues of each group was measured and analyzed. The results (Fig. 7A and B) revealed that, compared with the sham group, the extent of mTOR phosphorylation in the CPC group was significantly increased $(\mathrm{P}<0.05)$. Compared with the CPC group, the extent of mTOR phosphorylation in the 2, 4 and $6 \mathrm{mg} / \mathrm{kg}$ Pani groups was notably decreased (all $\mathrm{P}<0.05$ ). Compared with the $2 \mathrm{mg} / \mathrm{kg}$ Pani group, the extent of mTOR phosphorylation in the 4 and $6 \mathrm{mg} / \mathrm{kg}$ Pani groups was markedly reduced (both $\mathrm{P}<0.05)$. There was no significant difference between the 4 and $6 \mathrm{mg} / \mathrm{kg}$ Pani groups $(\mathrm{P}>0.05)$, and the extent of mTOR phosphorylation was lowest in the sham group. These results indicate that the EGFR monoclonal antibody Pani inhibited the phosphorylation of mTOR, thus inhibiting CPC lesions.

\section{Discussion}

High stone recurrence rates and biliary restenosis rates in patients with hepatolithiasis have been identified to be closely associated with CPC following surgery, however, effective strategies have not been found (19). It was confirmed that the EGFR inhibitor AG-1478 has a potent antiproliferative function on proliferative cholangitis and is a potential candidate for the treatment of proliferative cholangitis (14). In addition to antibody therapy, proliferating cell nuclear antigen short hairpin RNA therapy can more effectively inhibit the excessive proliferation of collagen fibers and excessive secretion of mucus in the bile duct of PC lesions, and may prevent biliary tract restenosis and postoperative biliary stone recurrence (20). The present study investigated the role of another EGFR inhibitor, Pani, in CPC. Consequently, it was found that Pani can inhibit the excessive proliferation and stone formation ability of bile duct mucosa in CPC with a receptor-saturation effect. A commercial EGFR antibody was used to measure its expression, which recognizes the residue around the Tyr1068 of human EGFR while Pani recognizes the residue around Ser468.

Primarily, the findings of the present study revealed that EGFR monoclonal antibody Pani inhibited excessive proliferation of the bile duct mucosa. CPC can thicken ongoing fibrosis and result in restenosis of the bile ducts and hyperplasia of submucosal glands, which may secrete further mucin-like glycoprotein (5). A previous study suggested that patients with bile duct carcinoma showed somatic mutation of EGFR in the tyrosine kinase region, which can induce signals that maintain cell survival and proliferation (21). A study conducted by Miyata et al revealed that ZD1839, a selective EGFR inhibitor, suppressed cell growth and the radiation-induced phosphorylation of EGFR in bile duct carcinoma cell lines (22). Pani has been previously reported to effectively inhibit EGFR wild-type dimerization and activation (23). Pani inhibits the binding of EGF and transforming growth factor- $\alpha$ to the receptor, resulting in the internalization of receptor-antibody complex, which can inhibit the autophosphorylation of ligand-induced EGFR tyrosine, thus inhibiting the EGFR pathway (24). Additionally, the results of the present study showed that the EGFR monoclonal antibody Pani inhibited the secretion of mucin-like glycoprotein in the bile duct wall, thus 
A

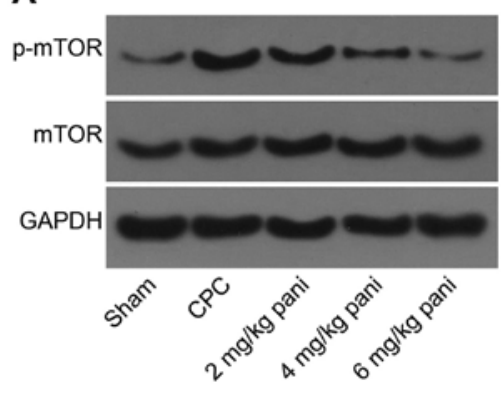

B

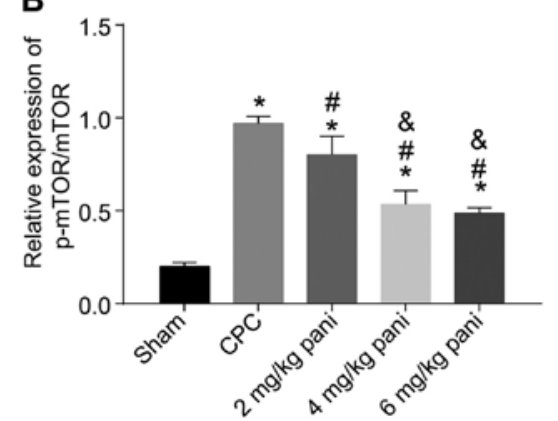

Figure 7. EGFR monoclonal antibody Pani inhibits the extent of mTOR phosphorylation and CPC lesions. (A) Gray values of mTOR and p-mTOR protein bands. (B) Ratio of the extent of mTOR phosphorylation to the protein level of mTOR, determined by western blot analysis (n=10). Data were analyzed by one-way analysis of variance and Tukey's test. ${ }^{*} \mathrm{P}<0.05$ vs. sham group; ${ }^{\#} \mathrm{P}<0.05$ vs. CPC group; ${ }^{\circledR} \mathrm{P}<0.05$ vs. 2 mg/kg Pani group. Pani, panitumumab; EGFR, epidermal growth factor receptor; CPC, chronic proliferative cholangitis; mTOR, mammalian target of rapamycin; p-, phosphorylated; GAPDH, glyceraldehyde-3-phosphate dehydrogenase.

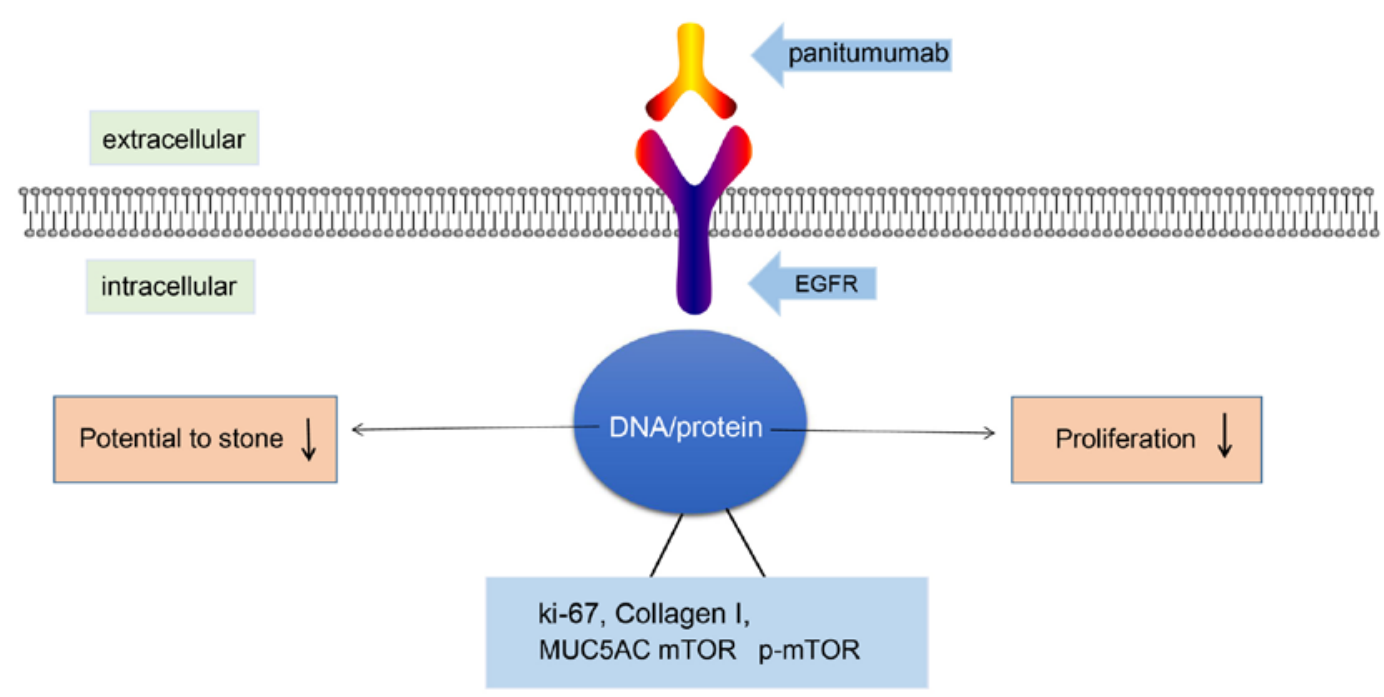

Figure 8. Schematic diagram of Pani regulating the proliferation and stone-formation potential of the bile duct mucosa in CPC. As an EGFR monoclonal antibody, Pani can bind to EGFR, which downregulates its expression and is associated with proliferation and stone-formation. This effectively inhibits the excessive proliferation and stone-formation potential of the bile duct mucosa in CPC. Pani, panitumumab; EGFR, epidermal growth factor receptor; CPC, chronic proliferative cholangitis; MUC5AC, mucin 5AC; mTOR, mammalian target of rapamycin; p-mTOR, phosphorylated mTOR.

effectively reducing the bile viscosity, aggregation and deposition of stone-forming elements. Mucin-like glycoprotein, with the potent lithogenic tendency of bile, together with bile duct restenosis, elevates the stone recurrence rate (5). Mucin-like glycoproteins, a secretory product of the gallbladder epithelium, are conducive to the formation of matrix or nucleus in gallstones and other biomineralization systems, and certain acidic glycoproteins have been reported to be involved in bile, gallstones, and lithiasis (25). In our previous study, it was found that the activation of EGFR increased mucin expression in the airway epithelium in vivo and normal human bronchial epithelial cells in vitro (26).

The results of the present study also demonstrated that Pani inhibited the positive expression of EGFR, and the expression of $\mathrm{Ki}-67$, type I collagen and MUC5AC, and these proteins can cause the formation of bile duct stones, thus inhibiting the overproliferation and potential of CPC. The efficacy also had a receptor-saturation effect. MUC5AC is the most important factor secreted by surface epithelial cells (27). MUC5AC is a prominent component of airway mucus, and its hypersecretion is a main sign in patients with chronic inflammatory airway diseases (28). Kim et al found that the addition of EGFR markedly elevated the level of MUC5AC in cultured human airway epithelial cells (26). Ki-67, as a proliferation marker, has been previously found to be exclusively expressed in proliferating cells (29). It is associated with various clinicopathological indicators, including tumor subtype, tumor size, tumor invasiveness and recurrence rate in pituitary neoplasia (30). $\mathrm{Ki}-67$ is expressed at high levels in hepatolithiasis and bile duct carcinoma tissues, reflecting a high metabolic proliferation activity and correlating with bile duct epithelial and secondary hyperplasia in hepatolithiasis and cholangitis (31). Collagen, a main constituent of the extracellular matrix, is found at high levels in several types of cancer, and affects the tumor microenvironment by enhancing the number of macrophages and endothelial cells (32). The level of type I collagen increases significantly with the progression of fibrosis staging in patients with chronic hepatitis C virus (33). It has also been reported that the transactivation of EGFR regulates the high glucose-induced upregulation of type I collagen via the phos- 
phoinositide 3-kinase-protein kinase Cb1-Akt signaling pathway in mesangial cells (34).

Furthermore, Pani was shown to inhibit the BrdU-positive rate and activity of $\beta-\mathrm{G}$. $\beta-\mathrm{G}$ is a potent tumor marker for cancer diagnosis and pro-drug therapies, and its elevated level in tumors is considered to be due to tumor overexpression and release from tumor tissues or tumor-infiltrating immune cells (35). Bacterial $\beta-\mathrm{G}$, extensively present in intestinal microflora, is also involved in metabolism and detoxification in mammals, and the decreased activity of $\beta-\mathrm{G}$ induced by Pani monoclonal antibody in the present study may refer to relieved CPC (36). The Pani monoclonal antibody reduces the extent of mTOR phosphorylation by inhibiting the gene expression of EGFR, thus inhibiting CPC lesions. mTOR, as an important regulator in cell-signaling pathways that are commonly deregulated in cancer, regulates cell growth and survival by connecting with nutrient and hormonal signals $(37,38)$. AKT, activated by EGFR, can regulate the activation of mTOR, and EGFR is positively associated with the expression of p-mTOR (39).

In conclusion, the data obtained in the present study demonstrated that the EGFR monoclonal antibody Pani can effectively suppress the excessive proliferation and stone-formation potential of the bile duct mucosa in CPC with a receptor saturation effect (Fig. 8). Pani offers promise as a treatment for the prevention and cure of intrahepatic choledocholithiasis caused by CPC. However, a positive therapeutic control was not designed in the present study, as no other drug with the same mechanism as Pani has been found to date. Therefore, only a blank control was selected. In the future, large-scale experiments with a positive therapeutic control are required to further verify the results obtained in the present study and to identify more effective treatments for CPC.

\section{Acknowledgements}

Not applicable.

\section{Funding}

No funding was received.

\section{Availability of data and materials}

The datasets used and/or analyzed during the current study are available from the corresponding author on reasonable request.

\section{Authors' contributions}

SHL and XFC designed the study. ZBX and JZ collated the data, designed and developedthe database XFC and ZBX carried out data analyses and produced the initial draft of the manuscript. All authors have read and approved the final submitted manuscript.

\section{Ethics approval and consent to participate}

All animal experiments performed conformed to the management of local laboratory animals guidelines and Medical Ethics Committee of Nanfang Hospital (Guangzhou, China).

\section{Patient consent for publication}

Not applicable.

\section{Competing interests}

The authors declare that they have no competing interests.

\section{References}

1. Jiang L, Jiang LS, Yan LN, Li FY, Wang W, Cheng NS and Wen TF: Effects of epidermal growth factor receptor inhibitor genistein on proliferative cholangitis in rats. J Surg Res 162: 59-67, 2010.

2. Li FY, Cheng NS, Cheng JQ, Mao H, Zhou Y, Jiang LS and Li N: Proliferating cell nuclear antigen shRNA treatment attenuates chronic proliferative cholangitis in rats. J Gastroenterol Hepatol 24: 920-926, 2009.

3. Li FY, Cheng NS, Mao H, Jiang LS, Cheng JQ, Li QS and Munireddy S: Significance of controlling chronic proliferative cholangitis in the treatment of hepatolithiasis. World J Surg 33: 2155-2160, 2009.

4. Asano T, Shoda J, Ueda T, Maruyama T, Kawamoto T, Sugimoto Y, Ichikawa A and Tanaka N: Involvement of prostaglandin E2 and its specific receptor subtype EP4 in chronic proliferative cholangitis in the bile ducts of patients with hepatolithiasis. Gastroenterology 124: A246-A246, 2003.

5. Koh YX, Chiow AK, Chok AY, Lee LS, Tan SS and Ibrahim S: Recurrent pyogenic cholangitis: Disease characteristics and patterns of recurrence. ISRN Surg 2013: 536081, 2013.

6. Li F, Cheng J, He S, Li N, Zhang M, Dong J, Jiang L, Cheng N and Xiong $\mathrm{X}$ : The practical value of applying chemical biliary duct embolization to chemical hepatectomy for treatment of hepatolithiasis. J Surg Res 127: 131-138, 2005.

7. Okines AF, Ashley SE, Cunningham D, Oates J, Turner A, Webb J, Saffery C, Chua YJ and Chau I: Epirubicin, oxaliplatin, and capecitabine with or without panitumumab for advanced esophagogastric cancer: Dose-finding study for the prospective multicenter, randomized, phase II/III REAL-3 trial. J Clin Oncol 28: 3945-3950, 2010

8. Di Nicolantonio F, Martini M, Molinari F, Sartore-Bianchi A, Arena S, Saletti P, De Dosso S, Mazzucchelli L, Frattini M, Siena S and Bardelli A: Wild-type BRAF is required for response to panitumumab or cetuximab in metastatic colorectal cancer. J Clin Oncol 26: 5705-5712, 2008.

9. Peeters M, Price TJ, Cervantes A, Sobrero AF, Ducreux M, Hotko Y, Andre T, Chan E, Lordick F, Punt CJ, et al: Randomized phase III study of panitumumab with fluorouracil, leucovorin, and irinotecan (FOLFIRI) compared with FOLFIRI alone as second-line treatment in patients with metastatic colorectal cancer. J Clin Oncol 28: 4706-4713, 2010.

10. Cohenuram M and Saif MW: Panitumumab the first fully human monoclonal antibody: From the bench to the clinic. Anticancer Drugs 18: 7-15, 2007.

11. Keating GM: Panitumumab: A review of its use in metastatic colorectal cancer. Drugs 70: 1059-1078, 2010.

12. Lacouture ME, Mitchell EP, Piperdi B, Pillai MV, Shearer H, Iannotti N, Xu F and Yassine M: Skin toxicity evaluation protocol with panitumumab (STEPP), a phase II, open-label, randomized trial evaluating the impact of a pre-Emptive Skin treatment regimen on skin toxicities and quality of life in patients with metastatic colorectal cancer. J Clin Oncol 28: 1351-1357, 2010.

13. Hecht JR, Patnaik A, Berlin J, Venook A, Malik I, Tchekmedyian S, Navale L, Amado RG and Meropol NJ: Panitumumab monotherapy in patients with previously treated metastatic colorectal cancer. Cancer 110: 980-988, 2007.

14. Li F, Zhou Y, Cheng N, Mao H, Jiang L, Li N, Li Q, de Jong MC and Pawlik TM: Epidermal growth factor receptor as a target for anti-proliferative treatment of proliferative cholangitis in hepatolithiasis. J Surg Res 166: 87-94, 2011.

15. Ji YY, Wang ZD, Wang SF, Wang BT, Yang ZA, Zhou XR, Lei NN and Yue WN: Ischemic preconditioning ameliorates intestinal injury induced by ischemia-reperfusion in rats. World $\mathrm{J}$ Gastroenterol 21: 8081-8088, 2015.

16. Livak KJ and Schmittgen TD: Analysis of relative gene expression data using real-time quantitative PCR and the 2(-Delta Delta C(T)) method. Methods 25: 402-408, 2001. 
17. Li N, Xiao LJ, Chen SW, Li L, Xiao BL, Chen WB, Gao XK and Gu SJ: Mucus histochemical study of bilirubin cholangiolithiasis in rabbit model. Hua Xi Yi Ke Da Xue Xue Bao 20: 417-420, 1989 (In Chinese)

18. Ho KJ, Lin XZ, Yu SC, Chen JS and Wu CZ: Cholelithiasis in Taiwan. Gallstone characteristics, surgical incidence, bile lipid composition, and role of beta-glucuronidase. Dig Dis Sci 40: 1963-1973, 1995

19. Li FY, Cheng NS, Cheng JQ, Mao H, Jiang LS, Li QS and Zhou Y: Practical value of applying cdc2 kinase shRNA to chronic proliferative cholangitis in treatment of hepatolithiasis. Hepatogastroenterology 56: 1477-1482, 2009.

20. Li FY, Cheng NS, Cheng JQ, Mao H, Jiang LS, Li N and He S: Treatment of chronic proliferative cholangitis with c-myc shRNA. World J Gastroenterol 15: 95-101, 2009.

21. Leone F, Cavalloni G, Pignochino Y, Sarotto I, Ferraris R, Piacibello W, Venesio T, Capussotti L, Risio M and Aglietta M: Somatic mutations of epidermal growth factor receptor in bile duct and gallbladder carcinoma. Clin Cancer Res 12: 1680-1685, 2006.

22. Miyata H, Sasaki T, Kuwahara K, Serikawa M and Chayama K The effects of ZD1839 (Iressa), a highly selective EGFR tyrosine kinase inhibitor, as a radiosensitiser in bile duct carcinoma cell lines. Int J Oncol 28: 915-921, 2006.

23. Gajadhar AS, Bogdanovic E, Munoz DM and Guha A: In situ analysis of mutant EGFRs prevalent in glioblastoma multiforme reveals aberrant dimerization, activation, and differential response to anti-EGFR targeted therapy. Mol Cancer Res 10: 428-440, 2012.

24. Peeters M, Balfour J and Arnold D: Review article: Panitumumab-a fully human anti-EGFR monoclonal antibody for treatment of metastatic colorectal cancer. Aliment Pharmaco Ther 28: 269-281, 2008.

25. Imano M, Satou T, Itoh T, Takeyama Y, Yasuda A, Peng YF Shinkai M, Haji S, Yasuda C, Nakai T, et al: An immunohistochemical study of osteopontin in pigment gallstone formation. Am Surg 76: 91-95, 2010.

26. Kim S, Schein AJ and Nadel JA: E-cadherin promotes EGFR-mediated cell differentiation and MUC5AC mucin expression in cultured human airway epithelial cells. Am J Physiol Lung Cell Mol Physiol 289: L1049-L1060, 2005.

27. Barbier D, Garcia-Verdugo I,Pothlichet J, Khazen R, Descamps D, Rousseau K, Thornton D, Si-Tahar M, Touqui L, Chignard M and Sallenave JM: Influenza A induces the major secreted airway mucin MUC5AC in a protease-EGFR-extracellular regulated kinase-Sp1-dependent pathway. Am J Respir Cell Mol Biol 47: $149-157,2012$

28. Shao MX and Nadel JA: Dual oxidase 1-dependent MUC5AC mucin expression in cultured human airway epithelial cells. Proc Natl Acad Sci USA 102: 767-772, 2005.
29. Bullwinkel J, Baron-Luhr B, Ludemann A, Wohlenberg C, Gerdes $\mathrm{J}$ and Scholzen T: $\mathrm{Ki}-67$ protein is associated with ribosomal RNA transcription in quiescent and proliferating cells. J Cell Physiol 206: 624-635, 2006.

30. Salehi F, Agur A, Scheithauer BW, Kovacs K, Lloyd RV and Cusimano M: Ki-67 in pituitary neoplasms: A review-part I. Neurosurgery 65: 429-437, 2009.

31. Wang P, He Y, Ma X, Sun B, Huang B, Zhu C and Liu Y: Expression and significance of COX-2 and Ki-67 in hepatolithiasis with bile duct carcinoma. Med Sci Monit 21: 2943-2949, 2015.

32. Liang H, Li X, Chen B, Wang B, Zhao Y, Zhuang Y, Shen H, Zhang $Z$ and Dai J: A collagen-binding EGFR single-chain Fv antibody fragment for the targeted cancer therapy. J Control Release 209: 101-109, 2015.

33. Attallah AM, Mosa TE, Omran MM, Abo-Zeid MM, El-Dosoky I and Shaker YM: Immunodetection of collagen types I, II, III, and IV for differentiation of liver fibrosis stages in patients with chronic HCV. J Immunoassay Immunochem 28: 155-168, 2007.

34. Wu D, Peng F, Zhang B, Ingram AJ, Kelly DJ, Gilbert RE, Gao B, Kumar S and Krepinsky JC: EGFR-PLCgammal signaling mediates high glucose-induced PKCbeta1-Akt activation and collagen I upregulation in mesangial cells. Am J Physiol Renal Physiol 297: F822-F834, 2009.

35. Su YC, Cheng TC, Leu YL, Roffler SR, Wang JY, Chuang CH, $\mathrm{Kao} \mathrm{CH}$, Chen $\mathrm{KC}$, Wang HE and Cheng TL: PET imaging of beta-glucuronidase activity by an activity-based 124I-trapping probe for the personalized glucuronide prodrug targeted therapy. Mol Cancer Ther 13: 2852-2863, 2014.

36. Chen M, Cheng KW, Chen YJ, Wang CH, Cheng TC, Chang KC, Kao AP and Chuang KH: Real-time imaging of intestinal bacterial $\beta$-glucuronidase activity by hydrolysis of a fluorescent probe. Sci Rep 7: 3142, 2017.

37. Guertin DA and Sabatini DM: Defining the role of mTOR in cancer. Cancer Cell 12: 9-22, 2007.

38. Feldman ME, Apsel B, Uotila A, Loewith R, Knight ZA, Ruggero D and Shokat KM: Active-site inhibitors of mTOR target rapamycin-resistant outputs of mTORC1 and mTORC2. PLoS Biol 7: e38, 2009.

39. Schmid K, Bago-Horvath Z, Berger W, Haitel A, Cejka D, Werzowa J, Filipits M, Herberger B, Hayden $\mathrm{H}$ and Sieghart W: Dual inhibition of EGFR and mTOR pathways in small cell lung cancer. Br J Cancer 103: 622-628, 2010.

This work is licensed under a Creative Commons Attribution-NonCommercial-NoDerivatives 4.0 International (CC BY-NC-ND 4.0) License. 